Parasitology Open

cambridge.org/pao

\section{Review}

Cite this article: Kumar A, Pandey SC, Samant $M$ (2018). Slow pace of antileishmanial drug development. Parasitology Open 4, e4, 1-11. https://doi.org/10.1017/pao.2018.1

Received: 5 November 2017

Revised: 21 December 2017

Accepted: 28 December 2017

\section{Key words:}

Challenges; drug; leishmaniasis; slow progress; target

\section{Author for correspondence:}

Mukesh Samant,

E-mail: mukeshsamant@gmail.com

\title{
Slow pace of antileishmanial drug development
}

\section{Awanish Kumar ${ }^{1}$, Satish Chandra Pandey ${ }^{2}$ and Mukesh Samant ${ }^{2}$}

${ }^{1}$ Department of Biotechnology, National Institute of Technology, Raipur (Chhattisgarh), India and ${ }^{2}$ Cell and Molecular Biology Laboratory, Department of Zoology, Kumaun University SSJ campus, Almora, Uttarakhand, India (c) Cambridge University Press 2018. This is an Open Access article, distributed under the terms of the Creative Commons Attribution licence (http://creativecommons.org/licenses/ by/4.0/), which permits unrestricted re-use, distribution, and reproduction in any medium, provided the original work is properly cited.

\section{Abstract}

The protozoan parasite Leishmania is endemic in large parts of the world which causes leishmaniasis. Its visceral form is fatal if not treated and is caused mostly by Leishmania donovani, Leishmania infantum and Leishmania chagasi. Given the difficulties linked to vector (sandfly) control and the lack of an effective vaccine, the control of leishmaniasis relies mostly on chemotherapy. Unfortunately, the prevalence of parasites becoming resistant to the firstline drug pentavalent antimony $(\mathrm{SbV})$ is increasing worldwide. Few alternative drugs are available that includes amphotericin B, pentamidine and miltefosine (oral). Already, decreases in efficacy, resistance and toxicity have been noted against these drugs. Dry antileishmanial pipeline further indicates the slow pace of drug discovery in this field where resistance as a major barrier. Full understanding of the genetic and molecular basis of the parasite is lagging. Since leishmaniasis is a neglected disease and occurs predominantly in the developing world largely, therefore, it is unaddressed. The pharma industry argues that development of the new drug is too costly and risky to invest in low return neglected diseases is very high. Research is also needed to identify new and effective drug targets. The lack of drug research and development for neglected diseases will require some new strategies. We have discussed the various cause of slow pace of antileishmanial drug discovery in this review to pay attention of researchers and also take the public and private initiative to make the process fast for new antileishmanial drug development.

\section{Introduction}

Leishmaniasis, with three basic clinical manifestations of the disease: cutaneous (CL), mucocutaneous (MCL) and visceral leishmaniasis (VL) caused by over 15 different species of the intracellular protozoan parasite Leishmania. With an estimated 12 million cases of leishmaniasis worldwide and 1.5-2 million new cases reported each year (Herwaldt, 1999). The parasite is primarily found in South America, Asia, southern Europe and Africa (Guerin et al. 2002). Since there is no antileishmanial vaccine is clinically available, control of Leishmaniasis relies almost exclusively on chemotherapy. For the past 7 decades pentavalent antimonials constituted the standard antileishmanial treatment worldwide, however, the last 20 years their clinical value was imperiled due to the widespread emergence of resistance to these agents in Bihar, India, where more than $50 \%$ of VL cases occur globally (Sundar et al. 2007). The availability of molecular methods, genome sequence, proteomic methods to the study Leishmania biology is practical and quite possible. Researchers should have to apply these methods and effective tools to the study of resistance mechanisms/novel drug targets and speed up the process of antileishmanial drug discovery.

Laboratory-induced drug resistance and field isolate resistance mechanism is partly understood in Leishmania. The high-level resistance to antimony observed in Leishmania can be due to decreased drug uptake and simultaneous selection of loss in metal reduction (Faraut-Gambarelli et al. 1997; Rojas et al. 2006). In contrast to in vitro selected strains, resistance to $\mathrm{Sb}(\mathrm{V})$ in Leishmania field isolates is not well understood (Carrio et al. 2001; Hadighi et al. 2006). Other available antileishmanial drugs are also showing resistance in different part of the world and resistance mechanism is unclear. Current studies with field isolates of Leishmania (Lira et al. 1999; Kumar et al. 2010) suggest similarities and differences with laboratory-resistant isolates but it is not yet clear whether any of the highlighted mechanisms is central to the resistance phenotype of field isolates. Understanding how antileishmanial drugs work and why they sometimes fail is fundamental to the optimal use of the existing formulations and is also likely to be instructive in the development of new therapies. It, therefore, appears quite clear that the cadence of antileishmanial drug development has not kept pace with the clinical needs. In this review, we further discuss the antileishmanial drug developed in past decades, current scenario of those drugs, emerging/novel drug targets, and challenges of antileishmanial drug development.

\section{Journey of antileishmanial drugs development}

The therapeutic options for Leishmania infections are quite limited and include only a few drugs (Fig. 1). The timeline of these drug discoveries or uses is explained in Fig. 2 that 

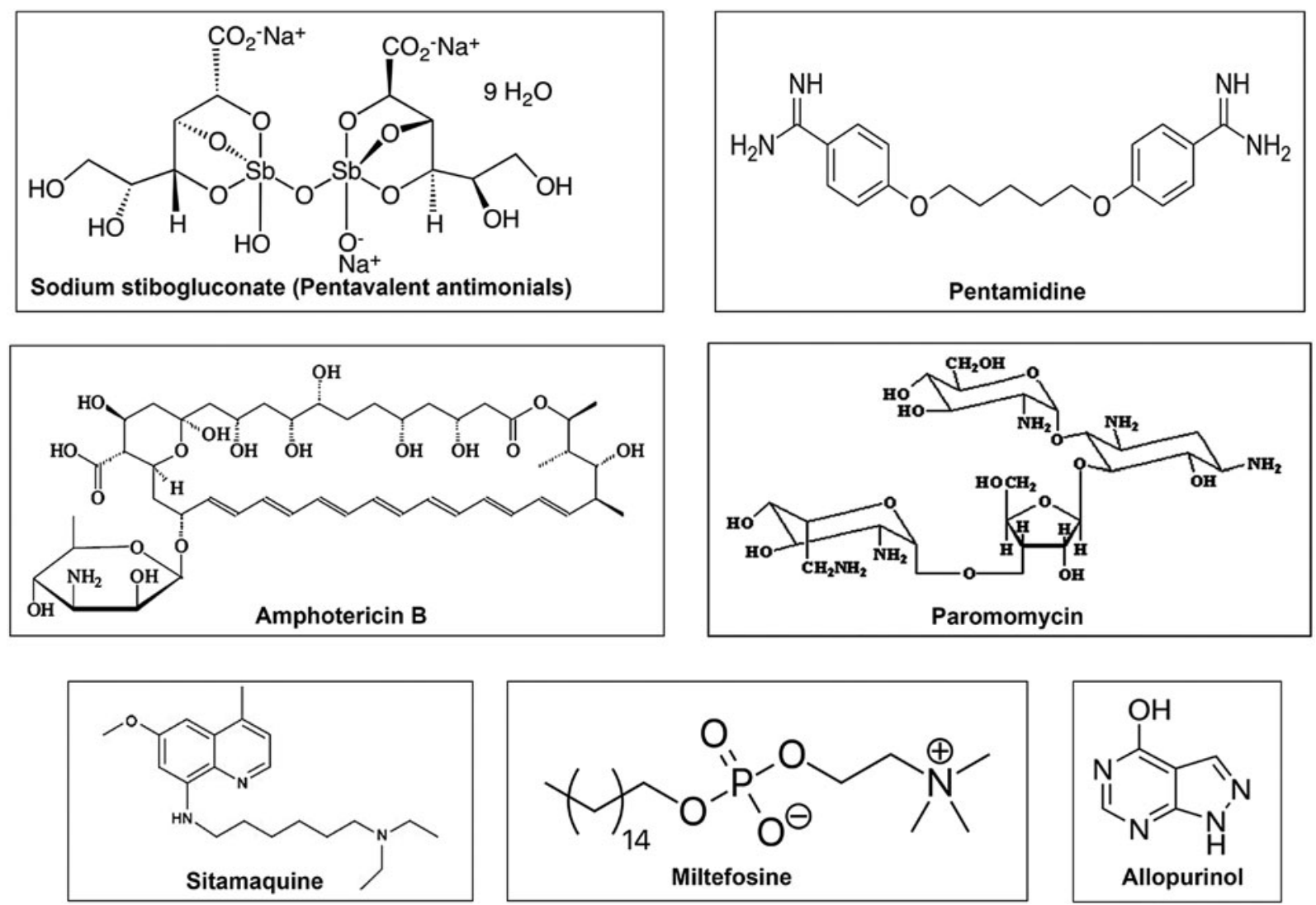

Fig. 1. Chemical structure of few drugs used as therapeutic options for Leishmania infections. Sodium stibogluconate is first line antileishmanials. Pentamidine, Amphotericin B and Parmomycin are second-line drugs, exhibited to be effective against CL and VL. Miltefosine, allopurinol and sitamaquine have shown oral activity against Leishmaniasis and are in phase III/IV clinical trial.

indicated the slow pace of antileishmanial discovery. Only one new class of antileishmanial drugs in terms of oral formulation has been developed in the last 20-30 years but they are also showing resistance now a day. Route of administration, mechanism of action and side effect of available antileishmanials are summarized and discussed in Table 1. Due to unavailability of an effective vaccine against leishmaniasis, drugs are only the important available means for the treatment.

\section{Preliminary/initial antileishmanials}

Urea stibamine (Urea salt of Stibnic acid) was used as a first effective drug against Leishmania donovani in 1920. It saved thousands of lives in India from 1920 to 1930. After that potassium antimony tartrate (Tarter emetic) was started to use against Leishmania in Vianna. Stibamine and stibacetin were also used for the treatment of Leishmania but showed few side-effects. Then pentavalent antimonials were developed as the first line of drug for the treatment of Leishmaniasis with reduced side- effects at that time.

\section{First-line antileishmanials}

The pentavalent antimonials were first introduced in 1945 and remained the standard drugs for about 6 decades. The two compounds currently available for clinical use are sodium stibogluconate [(SSG) also known as sodium antimony gluconate (SAG) and its trade name is Stibanate/Pentostam)] and Meglumine antimoniate (also known as $\mathrm{N}$-methylglucamine antimoniate and its trade name is Glucantime/Prostib). Stibogluconate $\{\mathrm{Sb}(\mathrm{V})\}$ under the brand of Pentostam has been manufactured by GlaxoWellcome which contains SSG. Using intracellular susceptibility testing, parasites isolated from $\mathrm{Sb}(\mathrm{V})$ unresponsive patients were found to be more resistant to $\mathrm{Sb}(\mathrm{V})$ as compared with parasites isolated from $\mathrm{Sb}(\mathrm{V})$ responsive patients (Kumar et al. 2009). Several side-effects have decreased the use of antimonials.

\section{Second-line antileishmanials}

The methanesulphonate or isethionate salts of pentamidine have been used as second-line drugs in the treatment of VL refractory to antimonial treatment. However, the effectiveness of pentamidine is rapidly declining in India, suggesting that Leishmania parasites are becoming resistant (Sundar, 2001). Amphotericin $\mathrm{B}$ (polyene macrolide antifungal antibiotic) was discovered in the 1960s, from a bacterium of genus Streptomyces and given to patients who are failed to treat with SSG/SAG or pentamidine. More effective lipid-associated formulations of Amphotericin B are also available. Its instability at high temperature, painful
Fig. 2. The timeline of antileishmanial drug discoveries from early 1920 to 2017, indicating the slow pace of antileishmanial discovery.

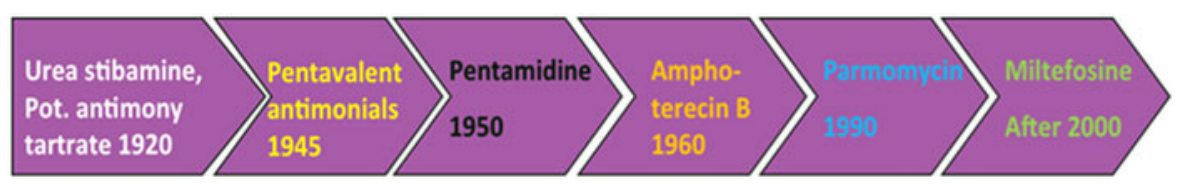


Table 1. Current antileishmanial drugs and their associated information

\begin{tabular}{|c|c|c|c|c|c|}
\hline $\begin{array}{l}\text { Antileishmanial } \\
\text { drugs }\end{array}$ & $\begin{array}{c}\text { Route of } \\
\text { administration }\end{array}$ & Mechanism & Side-effect & Resistance reports & References \\
\hline $\begin{array}{l}\text { Pentavalent } \\
\text { antimonials }\end{array}$ & $\begin{array}{l}\text { Intravenously or } \\
\text { intramuscularly }\end{array}$ & $\begin{array}{l}\text { - Pentavalent form converted to a lethal trivalent form in } \\
\text { amastigote. } \\
\text { - Activated within the amastigote, but not in the } \\
\text { promastigotes. } \\
\text { - Destroy Leishmania species by DNA degradation, } \\
\text { suggesting the role of apoptosis. } \\
\text { - Inhibits phosphorylation of ADP to ATP and citric acid } \\
\text { cycle. } \\
\text { - Interference of glycolysis and beta-oxidation of fatty } \\
\text { acids in amastigotes. } \\
\text { - Decreased energy and reducing equivalents for } \\
\text { antioxidant defence within amastigote }\end{array}$ & $\begin{array}{l}\text { - Venous thrombosis } \\
\text { - Acute electrocardiographic } \\
\text { changes } \\
\text { - Cardio, nephro and } \\
\text { hepatotoxicity } \\
\text { - Abdominal cramps, } \\
\text { headache } \\
\text { - Arthralgias, myalgias, } \\
\text { - Sterile abscesses at } \\
\text { intramuscular sites }\end{array}$ & $\begin{array}{l}\text { Resistance was developed in } \\
\text { the Bihar state of India and } \\
\text { reported from another province }\end{array}$ & $\begin{array}{l}\text { (Carter et al. 2006; Sereno et al. } \\
\text { 2001; Perry et al. 2015) }\end{array}$ \\
\hline Pentamidine & $\begin{array}{l}\text { Intravenous or } \\
\text { intramuscular }\end{array}$ & $\begin{array}{l}\text { - Inhibit parasite polyamine synthesis or binds with DNA } \\
\text { helix through electrostatic attraction between negative } \\
\text { phosphate groups and positive centre of amidine. } \\
\text { - Damage mitochondria and kinetoplast-DNA core of both } \\
\text { promastigotes and amastigotes. } \\
\text { Inhibit RNA polymerase and biosynthesis of nucleic acid, } \\
\text { proteins, phospholipids, polyamines }\end{array}$ & $\begin{array}{l}\text { - Rashes, fever, phlebitis, } \\
\text { sterile abscesses } \\
\text { - Hypotension } \\
\text { - Nephrotoxicity } \\
\text { - Hypoglycaemia } \\
\text { - Leucopenia, anaemia, } \\
\text { thrombocytopenia } \\
\text { - ECG changes }\end{array}$ & $\begin{array}{l}\text { Patients showed } \\
\text { unresponsiveness in India }\end{array}$ & (Kandpal and Tekwani, 1997) \\
\hline Amphotericin B & $\begin{array}{l}\text { Intravenously by } \\
\text { infusion }\end{array}$ & $\begin{array}{l}\text { - Binds to cell wall sterols but preferentially to ergosterol, } \\
\text { which is the major cell membrane sterol of Leishmania, } \\
\text { but not mammalian cell membranes causing pores which } \\
\text { alter ion balance, loss of low molecular weight } \\
\text { components such as glucose, amino acids and result in } \\
\text { cell death }\end{array}$ & $\begin{array}{l}\text { - Acute fever, chills, pain } \\
\text { - Anaphylaxis } \\
\text { - Hypotension, convulsions } \\
\text { - Hypokalaemia, } \\
\text { hypomagnesemia } \\
\text { - Nephrotoxicity }\end{array}$ & $\begin{array}{l}\text { Resistance reported in Bihar, } \\
\text { India and different part of the } \\
\text { world }\end{array}$ & $\begin{array}{l}\text { (Bern et al. 2006; } \\
\quad \text { Laniado-Laborin and } \\
\text { Cabrales-Vargas, 2009) }\end{array}$ \\
\hline Paromomycin & $\begin{array}{l}\text { Intramuscular } \\
\text { injections for VL and } \\
\text { as ointments for } \mathrm{CL}\end{array}$ & $\begin{array}{l}\text { - Paromomycin inhibits protein synthesis by binding to } \\
30 \mathrm{~S} \text { subunit ribosomes. } \\
\text { - Misreading and premature termination of mRNA } \\
\text { translation and causes the low concentration of } \mathrm{Mg}^{2}+ \\
\text { which induce dissociation. } \\
\text { - It also induces respiratory dysfunction in L. donovani } \\
\text { promastigotes }\end{array}$ & $\begin{array}{l}\text { - Skin rashes, burns } \\
\text { - Local pruritus } \\
\text { - Ototoxicity (eighth cranial } \\
\text { nerve toxicity) } \\
\text { - Nephrotoxicity }\end{array}$ & $\begin{array}{l}\text { Laboratory strain of Leishmania } \\
\text { tropica and L. donovani, } \\
\text { has developed resistance }\end{array}$ & (Jhingran et al. 2009) \\
\hline
\end{tabular}




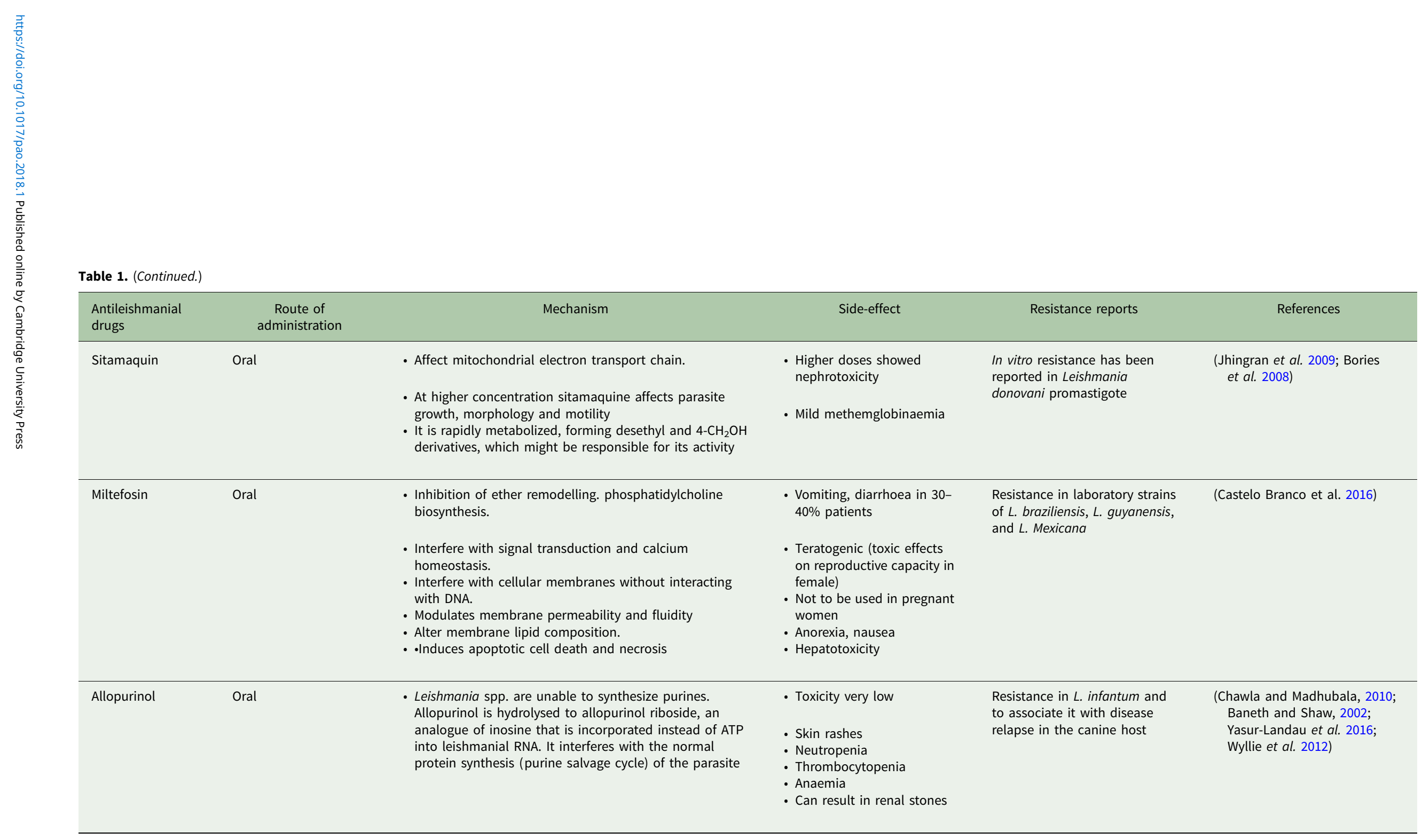


delivery and high cost limits its usefulness. Parmomycin (aminoglycoside antibiotic) another second-line drug, exhibited to be effective against CL in clinical studies in Russia, and in clinical trials with VL in the early 1990s. Paromomycin in combination with stibogluconate was used successfully for treating SSG unresponsive VL in India and Kenya (Moore and Lockwood, 2010).

\section{Oral antileishmanials}

Few agents (miltefosine, allopurinol, sitamaquine) have shown oral activity against Leishmaniasis. They are in phase III/IV clinical trial. Miltefosine was the first oral drug for VL. It is originally developed as an anticancer agent for topical treatment of skin metastases in 1992 but started to use for VL after 2000. Its activity against $L$. donovani was discovered in 1987 (Croft et al. 1987). Allopurinol (Hypoxanthine analogue) was used for CL in 1991 first time and its efficacy against Indian Kala-azar was first reported (Saenz et al. 1989). Allopurinol is ineffective as monotherapy against VL or CL. Now it is used with SSG for combination therapy. Sitamaquine (8-aminoquinoline and primaquine analogue) was developed by Walter Reed Army Institute of Research, the USA in 1994 for treatment. It is under development for over 8 years by Glaxo Smithkline, UK and Walter Reed Army Institute of Research, USA but the progress is very slow.

\section{Current scenario of available drugs}

\section{Pentavalent antimonials}

Despite the concern of proliferative resistance and various sideeffects, pentavalent antimonials (SbV), the generic SSG (pentosam), N-methyl-glucamine antimoniate (Glucantime) and branded meglumine antimoniate, etc. are being used as a drug of choice for the treatment of Leishmaniasis over more than 5 decades (Singh et al. 2006), but during the last two decades, antimonial resistance and therapeutic failures reached epidemic dimensions. Inadequate treatment in terms of dosing and duration and poor compliance promote the widespread antimonial resistance in an endemic area (Maltezou, 2010). Pentavalent antimonials (SbV) considered as a prodrug, which should convert to trivalent antimonials (SbIII) in order to demonstrate their antileishmanial activity (Carter et al. 2006). The reduction of pentavalent to trivalent compound takes place either in macrophages or in the parasite, however, it is still a dilemma (Shaked-Mishan et al. 2001). Parasite-mediated reduction has been found to be associated with the loss of reductase activity of parasite, which may also lead to drug resistance. Though the exact mechanism of action is unknown (Sereno et al. 2001), but both forms (SbIII and SbV) of antimonials destroy Leishmania species by DNA degradation, suggesting the role of apoptosis, adenosine diphosphate phosphorylation and oxidation of fatty acid. Furthermore, the antimonials are also concerned with increasing the efflux of intracellular thiols by multi-drug-resistant protein A (MRPA), glycolysis inhibition and $\mathrm{ABC}$ (ATP-binding cassette) transporters (El Fadili et al. 2005). In natural antimonial resistance, the impaired thiol metabolism results in inhibition of SbV activation and decreased uptake of the active form SbIII by amastigotes; this is accomplished by the lower expression aquaglyceroporin 1 gene, which is involved in the uptake of SbIII (Decuypere et al. 2005). The major cause of acquired resistance was the mismanagement of drug (Perry et al. 2015), due to its easy availability in its endemic regions along with the loss of drug activation by parasites. The transporters of pentamidine-resistant protein 1(PRP1) MRPA and ABC family that act as an efflux pump for antimonials, are also associated with antimony resistance (Coelho et al. 2003).

\section{Pentamidine}

A drug which can be used as a second-line drug against Leishmaniasis is pentamidine, an aromatic diamine. It contains two main salts methansulphonate and isothionatethatare mainly used for the treatment of VL. In India, initially it was used to treat $\mathrm{SbV}$ refractory patients, but due to its drawbacks of decreased efficiency and high resistance, it was no longer be used. Later on, this drug was also used in combination with other drugs. In a study, patients which were unresponsive to antimony revealed better response for a combination of a low dosage of pentamidine and allopurinol as compare to the full dosages of pentamidine (Das et al. 2001). Furthermore, a comparative study in Peru onmeglumine antimoniate (glucantime) and pentamidine against CL due to Leishmania braziliensis shows that glucantime was much more operational than pentamidine (Andersen et al. 2005). Although, its precise mode of action is not known, in a study (Kandpal and Tekwani, 1997) it is reported that in $L$. donovani promastigote the drug enters through polyamine and arginine transporters. Pentamidine is a highly toxic drug causes serious side-effects such as nephrotoxicity, hypoglycaemia and hypotension, etc. Although the mechanism of pentamidine resistance is not very well understood, ABC protein PRP1 can be associated with the resistance of pentamidine in the intracellular stage of Leishmania (Coelho et al. 2007).

\section{Amphotericin B}

Another drug which was previously being reported against Lieshmanial infection is Amphotericin B (AmB), a macrolide polyene antifungal drug widely used to treat systemic fungal infections (Marcondes et al. 2011). AmB is the drug of choice in the endemic areas of Bihar, India where antimonials resistance is common (Bern et al. 2006). AmB binds to membrane ergosterol, the predominant sterol of the fungal and leishmanial cell membrane. Even though it is highly effective but $\mathrm{AmB}$ also shows toxicity and its side-effects have been reported (Laniado-Laborin and Cabrales-Vargas, 2009). With its three clinical formulations, Ominous effects of plain AmB have been circumvented in which deoxycholate have been replaced by other lipids. These formulations are AmB colloidal dispersion (ABCD: Amphocil), liposomal AmB (L-AmB: Ambiosome) and $A m B$ lipid complex (ABL: Abelcit). These lipid formulations of $\mathrm{AmB}$ retain their antifungal activity and show very high efficacy to cure this fatal disease and are less toxic. In VL cases, liposomal $\mathrm{AmB}$ has been proved as an efficient drug but its high cost limits its use to a common man suffering from this lethal disease. In a study, it was found that the success of AmB treatment mainly depends on immunity status of the patient and indicates that consecutive relapse could increase exposure of AmB resistant isolates (Di Giorgio et al. 1999). Some investigations have shown that resistance to AmB was found to be associated with gene TarII 64.4 and TarII 512.2 amplification in L. tarentolae mutant cell lines (Singh et al. 2001) and overexpression of L-asparaginase gene in L. donovani (Singh et al. 2017). This finding warrants the possibility of resistance against the most successful drug.

\section{Paromomycin}

Paromomycin is broad-spectrum antibiotic produced by the bacterial spp. Streptomyces riomosus was originally developed as an oral drug for the treatment of intestinal protozoans in the 1960s. Later on, in 2002, it was first introduced as an antileishmanial drug in the form of PM sulphate (Williams et al. 1998). Due to its low cost, better efficacy, shorter duration of administration and fewer side-effects it became very popular and thought to be a candidate for the first line therapy for VL patients. However, VL 
and CL both can be cured by paromomycin but its finite accessibility limited its use in endemic regions (Thakur, 2003). Due to its limited use resistance is not yet recorded in patient treatment but reported in vitro in L. tropica and $L$. donovani (Jhingran et al. 2009). To overcome these problems PM is being reported in combination with liposome and albumin microsphere and thereby exhibiting better results (Wiwanitkit, 2012).

\section{Sitamaquine}

Sitamaquine was developed for the treatment of VL, chemically known as 4-methyl-6-methoxy-8-aminoquinoline. The main foredeal of this drug is its oral administration. The Kenyan phase II trial of sitamaquine gave an opinion about its efficacy, against VL and was well endured (Wasunna et al. 2005). However, despite its efficacy, some side-effects such as a headache, abdominal pain and kidney dysfunctioning were observed. The repercussion of Indian phase II trial was different from Kenyan trial (Jha et al. 2005). The Indian trial showed somewhat equal efficacy but the sideeffects observed were vomiting, dyspepsia, cyanosis, nephritic syndrome and glomerulonephritis. At higher concentration sitamaquine affects parasite growth, morphology and motility (Duenas-Romero et al. 2007). The mechanism involves electrostatic interaction between positively charged sitamaquine and phospholipid anionic polar head group and the insertion of the drug within the biological membrane is facilitated by phospholipid acyl chain (Coimbra et al. 2008). In clinical practices, the resistance against this drug has not been reported yet but in vitro resistance has been reported against $L$. donovani promastigote by selecting the drug pressure of sitamaquine at the concentration of $160 \mu \mathrm{M}$ (Bories et al. 2008). Due to less activity and efficacy, its further clinical trials were restricted seriously (Garnier et al. 2006).

\section{Miltefosine}

The recently introduced drug for the antilieshmanial activity is miltefosine, an alkylphosphocholine also known as hexadecylphosphocholine which was originally developed as anticancerous agent (Croft and Coombs, 2003). Being used as a first oral drug for the treatment of Indian VL it was considered a major breakthrough in antileishmanial chemotherapy (Sundar et al. 2006). Most of the studies (Sundar et al. 2000) shown that $>95 \%$ of patients were cured regularly at this dosing pattern. Later on, it was observed that few patients were falling back again after 912 months of successful treatment with miltefosine. After that this drug was also used in combination with ambisome and found working effectively, but some of its side-effects (Castelo Branco et al. 2016) raised questions about the effectiveness of this combination drug (Sundar et al. 2011). The clinical resistance is not yet clear but being an oral drug it was used improperly in endemic countries like India, that became the reason for its resistance. It is reported that single point mutation at LdRos3 and LdMT or overexpression of multidrug-resistant gene MDR1 rendered the parasites remarkably less sensitive to miltefosine, and this resistance persisted in vivo; cross-resistance with other antileishmanial was not detected (Perez-Victoria et al. 2001; Pérez-Victoria et al. 2006; Seifert et al. 2007). In all miltefosine resistant Leishmania lines decreased drug accumulation is the common phenomenon, and this may be due to decreased uptake, increased efflux, faster metabolism or altered plasma membrane permeability; the first two mechanisms have been described in experimental models of miltefosine resistance (Pérez-Victoria et al. 2006; Seifert et al. 2007). Further, its long half-life and teratogenic properties (Sundar and Olliaro, 2007) are the two major drawbacks that became the reason of its clinical resistance and eventually lead to the end of its use as a regular drug.

\section{Allopurinol}

Allopurinol is second line drug used for the treatment of leishmaniasis due to unresponsiveness or resistance of first-line antileishmanial drugs. The antileishmanial activity of allopurinol was first reported in 1974 (Pfaller and Marr, 1974). It is an analogue of purine and administered by oral route. Allopurinol is used alone or in combination with other drugs to the control of infection. Metabolization of allopurinol results into interruption of the pathogen's protein synthesis process, as they are not able to synthesize purines (Chawla and Madhubala, 2010). Specifically, it is attributed to the inhibition of the leishmanial enzyme hypoxanthine-guanine phosphoribosyl transferase (HGPRT). HGPRT takes part in the purine salvage pathway of the parasite. It converts dephosphorylated purines to nucleoside monophosphate leading to disrupted protein translation as well as the death of the parasite. Leishmaniasis has been treated for many years with allopurinol in domestic dogs and humans (Baneth and Shaw, 2002). Recently some researchers have reported resistance of allopurinol in L. infantum and associated it with disease relapse in the canine host dog because the dog is the main reservoir for this zoonotic infection (Yasur-Landau et al. 2016).

Beside above mentioned antileishmanial drugs few other compounds also been shown antiLeishmania potency, e.g. the anti-trypanosome drug fexinidazole showed potential for treating VL (Wyllie et al. 2012), Nitroimidazo-oxazole compound DNDI-VL-2098: an orally effective preclinical drug candidate (Gupta et al. 2014) and the $\mathrm{R}$ enantiomer of the antitubercular drug PA-824 as a potential oral treatment for VL (Patterson et al. 2013). The main point of concern of antileishmanial drug discovery is the stepwise increase in resistance. The current scenario is worst and research going on Leishmania cannot rule out about the future availability of the candidate leishmanial antigens/immunogens. So further it needs extensive study and validation of emerging potent and novel drug targets of Leishmania.

\section{Emerging and novel drug targets in Leishmania}

Discovery of new potential drug targets mainly depends on biochemical, metabolic pathways and their enzymes, which are substantive for the survival of the parasite. Particular enzymes which are present in the parasite and absent from mammalian cells are of great interest. However, still, mammalian enzymes, which have structural homology, might also provide objectives for antileishmanial therapy because report showed favorable interactions of inhibitors with the active pocket of parasite enzyme, without adversely affecting human enzyme (Singh et al. 2017) and this is the rationale of the listed potential target in Leishmania. They could be interesting and promising for future antileishmanial drug development.

\section{Enzymes of Trypanothione synthesis pathway}

Trypanothione (bis-glutathionyl spermidine) is an indispensable molecule, which protects Leishmania against oxidative stress. Two enzymes namely trypanothione reductase (TR) and trypanothione synthetase (TS) catalyse the synthesis of trypanothione. TS catalyses the synthesis of trypanothione from two molecules of spermidine and glutathione, then in the presence of NADPH, trypanothione is upheld in its reduced form by the enzyme TR (Fairlamb et al. 1985). Reduced trypanothione, in turn, reduces tryparedoxin (TX) followed by reduction of TX recycling enzyme tryparedoxin peroxidase (TP). Since, in Leishmania, this is the only pathway that is decisively implicated in maintaining oxidative stress, therefore, both $\mathrm{TP}$ and $\mathrm{TR}$ have been 
shown to be important drug targets. Null mutation of TR show attenuated infectivity (Dumas et al. 1997). The role of TR as potential targets for rational drug design has also been reviewed recently (Kumar et al. 2014). Thus, enzymes of Trypanothione synthesis pathway provide a promising drug target in trypanosomatids.

\section{Metacaspases}

Another kind of molecule which can be used as a drug target in Leishmania is metacaspase which is believed to cause apoptosis (Lee et al. 2007). Leishmania major metacaspase has been found to be essential for proper segregation of nucleus and kinetoplast of the parasite (Denise et al. 2006). It is reported that under peroxide stress, metacaspase causes apoptosis of parasite (Gonzalez et al. 2007). Since metacaspase are associated with chromosomal separation and survival of the parasite they can directly be used as a drug target(Meslin et al. 2011). So the molecules that can target on the biosynthetic machinery of metacaspase might be used as the effective antileishmanial agent. However, more studies are required to understand the entire role of leishmanial metacaspases.

\section{Enzymes of folate biosynthesis}

The key enzyme which is responsible for the production of thymidine in folate metabolism is DHFR (Booth et al. 1987). Using $\mathrm{NADPH}$ as cofactor it reduces dihydrofolate to tetrahydrofolate. As a result, DHFR inhibition stops thymidine biosynthesis and as a consequence, biosynthesis of DNA. Auspiciously DHFR has been crystallized from Trypanosoma cruzi and L. major and structural data between parasite and human enzymes may be achieved so that inhibitors of DHFR can be designed (Senkovich et al. 2009). An enzyme dihydrofolate reductase-thymidylate (DHFR-TS) is also associated with the survival of parasite and without this enzyme parasites are not able to survive in animal hosts (Veras et al. 1999). In addition, an approach using database mining to explore novel inhibitors of DHFR has also been made but it needs more focus to use DHFR as a drug target (Zuccotto et al. 1998). Despite these advantages, various resistance mechanisms to DHFR have been uncovered such as overexpression of the enzyme PTR-1 and DHFR-TS (Wang et al. 1997). The enzyme PTR-1 not only causes the reduction of biopterin to dihydrofolate and tetrahydrofolate but also reduces dihydrofolate to tetrahydrofolate. Therefore DHFR and PTR-1 can be used as more efficient drug targets.

\section{Topoisomerase}

DNA topoisomerases are involved in various biological processes like DNA replication, transcription, recombination, and repair and classified as type I and type II. DNA topoisomerases have been used as chemotherapeutic targets against Leishmania (Das et al. 2004). Camptothecin, a plant alkaloid which is an inhibitor of eukaryotic topoisomerase-I shows some inhibitory properties against T. brucei, T. cruzi and L. donovani (Bodley et al. 1995). A pentacyclic triterpenoid, Dihydrobetulinic acid (DHBA) which is a derivative of betulinic acid shows inhibitory properties against both Topoisomerase I and topoisomerase II of L. donovani (Chowdhury et al. 2003). Three isoflavanoids, smiranicin, lyasperin $\mathrm{H}$ and 8-prenylmucronulatol have been found to be observed with anti-leishmanial attribute and this activity has been correlated to inhibition of topoisomerase II and kDNA linearization (Salem and Werbovetz, 2005). Thus these enzymes should be structurally analysed so that specific inhibitors against Leishmania can be designed.

\section{Protein kinases}

Cyclin-dependent kinases (CDKs) are reported to play a significant role in cell division cycle, differentiation, transcription, and apoptosis. For their own activation, few CDKs requires active cyclins and for functional activation, few require phosphorylation which could be accomplished at their conserved threonine residues (t-loop) by cdc2 activating kinases (Affranchino et al. 1993). So in Leishmania, these cdc-2 activating kinases which are essential for the progression of the cell cycle can be used as potential drug targets. Two putative CDKs, LmexCRK3 and LmexCRK1 (Hassan et al. 2001) have also been found to be essential to the promastigotes form. CRK3 belongs to indirubin class, is found to be active throughout the life cycle in L. mexicana (Grant et al. 1998; Hassan et al. 2001). The chemical inhibitors of CRK3 deteriorate parasitic viability within macrophage, thus CRK3 can be used as a potential drug target. In another study on $L$. dono$v a n i$, recently it was found that glycogen synthase kinase (LdGSK3) is also associated with the control of cell cycle and apoptosis based on the indirubin test (Xingi et al. 2009). Thus, LdGSK3 in combination with CRK3 can be used as possible drug targets. Similarly, other cdks can also be diagnosed as potential drug targets.

\section{Mitogen-activated proteins kinases (MAPK)}

Mitogen-activated protein (MAP) kinases play a significant role in signal transduction. Moreover, they act as a regulator of cell differentiation, proliferation and apopotosis. Until now, 15 MAP kinases have been identified in L. mexicana (Wiese, 2007) and the most studied are LmxMPK, LmxMPK9 and LmxMKK (Bengs et al. 2005). These MAP kinases can further be evaluated as a potential drug target.

\section{Proteinases}

Proteinases are of four main types: serine, aspartate, cysteine and metalloenzyme. In case of parasitic protozoans most identified and characterized are cysteine proteinases (CPs). Because of structurally different from mammalian homologue and their role as a putative virulence factor in parasite-host cell interaction CPs have become of great interest as a potential drug target. More than 65 CPs have been observed from the genome sequence analysis of $L$. major and are further categorized into various types viz. CPA, $\mathrm{CPB}$ and $\mathrm{CPC}$. Furthur gene replacement studies of L. mexicana revealed the role of $\mathrm{CPA}, \mathrm{CPB}$ and $\mathrm{CPC}$ in host-parasite interaction. In a study when multicopy $\mathrm{CPB}$ gene array (Dcpb) was replaced by L. mexicana, BALB/c mice was observed with poor lesion growth with reduced virulence (Alexander et al. 1998). Some highly potent inhibitors (Semicarbazones, Thiosemicarbazones and Triazine Nitriles) of L. mexicana cysteine protease CPB have been reported that may also have useful efficacy against other important cysteine proteases (Schröder et al. 2013).

\section{Methionine aminopeptidase 2 (MetAP-2)}

MetAP-2 is a cellular metalloexopeptidase, participates in the late hydrolysis of the initiator methionine of protein synthesis (Walker KF, 1998). Fumagillin which is an inhibitor of MetAP-2 prevent the replication of $L$. donavani (Zhang et al. 2002).

\section{Microtubule-associated protein (MAP2)}

In past, parasitic microtubules have been identified as a potential target but due to the high toxicity of antimicrotubule drugs, its further use in regular practice was restricted. MAP2, an ethyl 
3-(chloroacetamido)-benzoate that is effective on diverse species of Leishmania, alters the organization of microtubule in the parasite. Its in vivo activity was observed in an L. major mice model by the important reduction of the parasite load in the liver, spleen and lymph node (Hiam et al. 2006).

\section{Enzymes of sterol biosynthesis}

The major growing sterols in Leishmania are ergosterol and stigmasterol, which is different from mammalian complimentary cholesterol. This can be used as an effective drug target. Ergosterol has two main functions: (1) it is a construction unit of the cell membrane and (2) it might play a significant role in the hormonal activity. Because of sterol based mechanism, AmB reveals its effectiveness against Leishmaniasis but due to $A m B$ resistance for Leishmania, it orders investigators to search an alternative drug of AmB. Azasterol, a class of s-adenosyl-L-methionine performs antileishmanial activity by inhibiting 24-methyltransferase (the vital enzyme in ergosterol biosynthesis) (Lorente et al. 2005). Other compounds such as azole and triazole inhibit $14 \alpha$-methylsterol 14-demethylase. Thus are effective against Leishmania. During the development of the novel drug, it must be in consideration that when the sterol profile of Leishmania get alters it metabolizes host sterol for its survival (Roberts et al. 2007).

\section{DEAD BOX RNA helicase}

DEAD-box RNA helicases are important in tumorigenesis and viral infection (Ariumi, 2014) so it represents a potent novel therapeutic target (Xu et al. 2011). In the case of Leishmania, ATP-dependent DEAD-box RNA helicase plays important role in RNA metabolism and cellular signalling. Recently it has been reported that a $67 \mathrm{kDa} \mathrm{DEAD}$-box ATP-dependent RNA helicase preventing antisense rRNA cleavage, and protecting rRNA from degradation and Leishmania from cell death (Padmanabhan et al. 2012). Further Leishmania DDX3 homologue of DEAD-box RNA helicase plays a central role in mitochondrial protein quality control under normal growth conditions and particularly upon stress by preventing ROS-mediated damage and polyubiquitinated protein accumulation in the mitochondrion (Padmanabhan et al. 2016). Our unpublished QSAR study also suggested many inhibitors for DEAD-box RNA helicase.

\section{Casein kinase 1 isoform 2 (CK1.2)}

Casine kinase is a member of the highly conserved Ser/Thr protein kinase family which play important role in signal transduction (Knippschild et al. 2005). CK1 contains six isoforms in Leishmania. LmjF35.1010 (LmCK1.2), the major isoform, has been validated pharmacologically as a drug target because CK1 shown to be essential for intracellular parasite survival and infectivity (Durieu et al. 2016). Two lead compounds have also been identified and selected as LmCK1.2 inhibitors based on their specificity, antileishmanial activity, the absence of cytotoxicity (Durieu et al. 2016). There is a further need to understand their mode of action and these compounds could also be used as pharmacological tools to study parasite-specific signal transduction.

\section{L-asparaginase}

L-asparaginases enzyme belongs to amidohydrolases family that catalyse the conversion of L-asparagine into L-aspartic acid and ammonia (Vimal and Kumar, 2017). The presence of genes coding for putative l-asparaginase enzymes in the L. donovani genome has given a hin towards the specific role of this enzyme in the survival of the parasite. Singh et al. (2017) have advocated that L-asparaginases could be a potential drug target against the pathogen Leishmania.

\section{Challenges in antileishmania drug development}

The current pace of antileishmanial drug development is very slow and it should be kept up with the clinical needs, particularly as resistance to current agents is being reported frequently and drug resistance mechanisms should be explored. The further slow pace of new antileishmanial drug development is due to: (1) different clinical manifestations, (2) a deficient market, (3) failure of public-health policy, (4) lack of public-private partnerships (PPPs) and (5) lack of technology transfer.

\section{Clinical problem}

Leishmaniasis is caused by 21 of 30 species of Leishmania that infect mammals (https://www.cdc.gov/dpdx/leishmaniasis/index. html). These include VL caused by the L. donovani complex; MCL is caused by parasite belongs to the braziliensis complex, such as L. braziliensis, L. panamensis, L. peruviana; and CL is caused by L. major in the Old World but in America this clinical form could be caused by parasite belongs to the subgenus Leishmania and Viannia. The different species are morphologically indistinguishable, but they can be differentiated by isoenzyme analysis, DNA sequence analysis or monoclonal antibodies (Hijjawi et al. 2016). Among CL, MCL and VL, VL is a fatal form in which the parasites have migrated to the vital organs (liver, bone marrow and spleen) of the body (Kumar et al. 2015). Up to $90 \%$ of the world's cases of VL are found in Bangladesh, Brazil, India, Nepal and Sudan. Wide and vast clinical manifestation of this disease is one major challenge in antileishmanial drug development (Pace, 2014).

\section{Deficient market}

Food and Drug Administration (FDA), USA approved thousands of new chemical entities from 1995 to 2016, but only a few were for infectious diseases. Among these anti-infectious agents, Miltefosine was approved as the only antileishmanial agent in 2014 in last 21 years (http://www.centerwatch.com/drug-information/fda-approved-drugs/year/2016). There is a more than the 10 -fold greater chance of a drug being brought to market for cancer, neurological disorders than for infectious disease. This number is negligible and matter of sorrow for the neglected disease leishmaniasis. Because the pharmaceutical industry argues that drug development is risky and too costly to invest in the lowreturn area such as leishmaniasis. This a most prominent reason for a limited number of new antileishmanial drugs marketed. The drugs for the neglected diseases working group is currently exploring the feasibility of not-for-profit initiative internationally that would focus on drug development projects for the most the neglected diseases like leishmaniasis. Such an initiative would remove the process of life-saving drugs development from a market-driven logic.

\section{Lack of strong public-health policy}

Public-health policy has an intense impact on health status. Good policies are not in use in developing and underdeveloped countries. Most of the developing countries spent $<\$ 20$ on all health programme per year per person (Sachs, 2002). In these circumstances, the market is too small to attract investors in the development of the drug for the diseases that mainly affect developing countries. The chronic neglected disease crisis calls for a substantial health policy and long-term response worldwide that and will 
definitely create a paradigm shift in health, research and development. The evidence sheds light that the public-health policy issues are limited in developing and underdeveloped countries. There should be an international pharmaceutical policy for all neglected diseases and a PPP sector come up and promote not-for-profit research and development capacity.

\section{Public-private partnerships}

Measures should be taken to overcome the above-discussed constraint and PPP could be a solution. It attempts to fill the gaps in the health needs of developing countries through the establishment of public-private networks and collaboration. The public sector includes aid agencies, international organizations, academia and government bodies and the private sector includes pharmaceutical industries, foundations, philanthropic institutions, and charities. Recently, some PPPs have started drug development activities in the pharmaceuticals sector, as a new paradigm. The PPP concept has recently evolved into product-based and more structured collaborations. The tropical disease research (TDR), WHO and the Walter Reed Army Institute of Research (WRAIR), Maryland, USA is a good example of public institutions working in partnership with the private sector on drug development programmes. The antimalarial drug mefloquine was discovered by the WRAIR and later developed jointly with industry and TDR (Gelband et al. 2004). However, company engagement is limited and doing initiative for AIDS, Malaria and Tuberculosis, because these diseases rank higher in the public-health priorities of developed countries than other neglected diseases and represent a potential market for the industry. For the neglected diseases such as leishmaniasis, PPP engagement and effort should be more and more.

\section{Technology transfer}

Capacity building and technology transfer have been promoted for many years by TDR, United Nations Development Programme, and Drugs for Neglected Diseases Initiatives (DNDI). FDA, $\mathrm{NIH}$ and several US university technology transfer offices have compiled a list of their technologies that relate to these specific neglected diseases (Allarakhia, 2013). This list is expected to function as an additional tool to facilitate the transfer of such technologies to potential licensee institutions worldwide for the development of effective medicine against neglected disease. Adopting approaches to transfer technologies offers the broadest benefit to populations in need. Practical issues confronted by technology transfer would be helpful in the development of products in neglected disease areas.

\section{Conclusion}

Despite impressive advances in science and technology we have failed to allocate sufficient resources to fight the diseases leishmaniasis. There are a deficiency and sluggishness of research and development into neglected diseases to control the re-emergence, develop more effective drugs, and overcome resistance for leishmaniasis to shorten the treatment. Only a few drugs are available for the treatment of leishmaniasis and the appearance of drug resistance is further complicating the control of this disease. A wide range of biological assays of the possible compounds should be performed with several strains and different parasite forms, and active compound should be reached to clinical trials immediately. To meet these challenges, a firm commitment by the pharmaceutical industry partnering with academics, novel chemical libraries and combining innovative screening strategies is required to achieve victory. This suggests that there is a need to come up with newer hit/leads which may help furthermore to combat with leishmaniasis and slow down the potential emergence of resistant Leishmania parasites.

Acknowledgements. Authors are thankful to Kumaun University SSJ campus, Almora (Uttarakhand), India and National Institute of Technology (NIT), Raipur (CG), India for providing a facility for this work.

Financial support. This study was financially supported by the Science and Engineering Research Board (SERB, India) young scientist grant YSS/2014/ 000773 awarded to M.S.. The funders had no role in study design, data collection and analysis, decision to publish, or preparation of the manuscript.

Conflict of interest. The authors have declared no conflict of interest.

\section{References}

Affranchino JL, Gonzalez SA and Pays E (1993) Isolation of a mitotic-like cyclin homologue from the protozoan Trypanosoma brucei. Gene 132, 75-82.

Alexander J, Coombs GH and Mottram JC (1998) Leishmania mexicana cysteine proteinase-deficient mutants have attenuated virulence for mice and potentiate a Th1 response. Journal of Immunology 161, 6794-6801.

Allarakhia M (2013) Open-source approaches for the repurposing of existing or failed candidate drugs: learning from and applying the lessons across diseases. Drug Design, Development and Therapy 7, 753.

Andersen EM, Cruz-Saldarriaga M, Llanos-Cuentas A, Luz-Cjuno M, Echevarria J, Miranda-Verastegui C, Colina O and Berman JD (2005) Comparison of meglumine antimoniate and pentamidine for peruvian cutaneous leishmaniasis. American Journal of Tropical Medicine and Hygiene 72, 133-137.

Ariumi Y (2014) Multiple functions of DDX3 RNA helicase in gene regulation, tumorigenesis, and viral infection. Frontiers in Genetics 5, 423.

Baneth G and Shaw SE (2002) Chemotherapy of canine leishmaniosis. Veterinary Parasitology 106, 315-324.

Bengs F, Scholz A, Kuhn D and Wiese M (2005) LmxMPK9, a mitogenactivated protein kinase homologue affects flagellar length in Leishmania mexicana. Molecular Microbiology 55, 1606-1615.

Bern C, Adler-Moore J, Berenguer J, Boelaert M, den Boer M, Davidson RN, Figueras C, Gradoni L, Kafetzis DA, Ritmeijer K, Rosenthal E, Royce C, Russo R, Sundar S and Alvar J (2006) Liposomal amphotericin B for the treatment of visceral leishmaniasis. Clinical Infectious Diseases 43, 917-924.

Bodley AL, Wani MC, Wall ME and Shapiro TA (1995) Antitrypanosomal activity of camptothecin analogs. Structure-activity correlations. Biochemical Pharmacology 50, 937-942.

Booth RG, Selassie CD, Hansch C and Santi DV (1987) Quantitative structureactivity relationship of triazine-antifolate inhibition of Leishmania dihydrofolate reductase and cell growth. Journal of Medicinal Chemistry 30, 1218-1224.

Bories C, Cojean S, Huteau F and Loiseau PM (2008) Selection and phenotype characterisation of sitamaquine-resistant promastigotes of Leishmania donovani. Biomedicine \& Pharmacotherapy 62, 164-167.

Carrio J, Riera C, Gallego M, Ribera E and Portus M (2001) In vitro susceptibility of Leishmania infantum to meglumine antimoniate in isolates from repeated leishmaniasis episodes in HIV-coinfected patients. Journal of Antimicrobial Chemotherapy 47, 120-121.

Carter KC, Hutchison S, Henriquez FL, Legare D, Ouellette M, Roberts CW and Mullen AB (2006) Resistance of Leishmania donovani to sodium stibogluconate is related to the expression of host and parasite gamma-glutamylcysteine synthetase. Antimicrobial Agents and Chemotherapy 50, 88-95.

Castelo Branco PV, Soares RE, de Jesus LC, Moreira VR, Alves HJ, de Castro Belfort MR, Silva VL and Ferreira Pereira SR (2016) The antileishmanial drug miltefosine (impavido(R)) causes oxidation of DNA bases, apoptosis, and necrosis in mammalian cells. Mutatation Ressearch Genetic Toxicology and Environmental Mutagenesis 806, 34-39.

Chawla B and Madhubala R (2010) Drug targets in Leishmania. Journal of Parasitic Diseases 34, 1-13.

Chowdhury AR, Mandal S, Goswami A, Ghosh M, Mandal L, Chakraborty D, Ganguly A, Tripathi G, Mukhopadhyay S, Bandyopadhyay S and Majumder HK (2003) Dihydrobetulinic acid induces apoptosis in Leishmania donovani by targeting DNA topoisomerase I and II: implications in antileishmanial therapy. Molecular Medicine 9, 26-36.

Coelho AC, Beverley SM and Cotrim PC (2003) Functional genetic identification of PRP1, an ABC transporter superfamily member conferring pentamidine resistance in Leishmania major. Molecular \& Biochemical Parasitology 130, 83-90. 
Coelho AC, Messier N, Ouellette M and Cotrim PC (2007) Role of the ABC transporter PRP1 (ABCC7) in pentamidine resistance in Leishmania amastigotes. Antimicrobial Agents and Chemotherapy 51, 3030-3032.

Coimbra ES, Goncalves-da-Costa SC, Costa BL, Giarola NL, Rezende-Soares FA, Fessel MR, Ferreira AP, Souza CS, Abreu-Silva AL and Vasconcelos EG (2008) A Leishmania (L.) amazonensis ATP diphosphohydrolase isoform and potato apyrase share epitopes: antigenicity and correlation with disease progression. Parasitology 135, 327-335.

Croft SL and Coombs GH (2003) Leishmaniasis--current chemotherapy and recent advances in the search for novel drugs. Trends in Parasitology 19, 502-508.

Croft SL, Neal RA, Pendergast W and Chan JH (1987) The activity of alkyl phosphorylcholines and related derivatives against Leishmania donovani. Biochemical Pharmacology 36, 2633-2636.

Das VN, Ranjan A, Sinha AN, Verma N, Lal CS, Gupta AK, Siddiqui NA and Kar SK (2001) A randomized clinical trial of low dosage combination of pentamidine and allopurinol in the treatment of antimony unresponsive cases of visceral leishmaniasis. The Journal of the Association of Physicians of India 49, 609-613.

Das A, Dasgupta A, Sengupta T and Majumder HK (2004) Topoisomerases of kinetoplastid parasites as potential chemotherapeutic targets. Trends in Parasitology 20, 381-387.

Decuypere S, Rijal S, Yardley V, De Doncker S, Laurent T, Khanal B, Chappuis F and Dujardin JC (2005) Gene expression analysis of the mechanism of natural $\mathrm{Sb}(\mathrm{V})$ resistance in Leishmania donovani isolates from Nepal. Antimicrobial Agents and Chemotherapy 49, 4616-4621.

Denise H, Poot J, Jimenez M, Ambit A, Herrmann DC, Vermeulen AN, Coombs GH and Mottram JC (2006) Studies on the CPA cysteine peptidase in the Leishmania infantum genome strain JPCM5. BMC Molecular Biology 7, 42.

Di Giorgio C, Faraut-Gambarelli F, Imbert A, Minodier P, Gasquet M and Dumon H (1999) Flow cytometric assessment of amphotericin B susceptibility in Leishmania infantum isolates from patients with visceral leishmaniasis. Journal of Antimicrobial Chemotherapy 44, 71-76.

Duenas-Romero AM, Loiseau PM and Saint-Pierre-Chazalet M (2007) Interaction of sitamaquine with membrane lipids of Leishmania donovani promastigotes. Biochimica et Biophysica Acta 1768, 246-252.

Dumas C, Ouellette M, Tovar J, Cunningham ML, Fairlamb AH, Tamar S, Olivier M and Papadopoulou B (1997) Disruption of the trypanothione reductase gene of Leishmania decreases its ability to survive oxidative stress in macrophages. EMBO Journal 16, 2590-2598.

Durieu E, Prina E, Leclercq $O$, Oumata N, Gaboriaud-Kolar N, Vougogiannopoulou K, Aulner N, Defontaine A, No JH and Ruchaud S (2016) From drug screening to target deconvolution: a targetbased drug discovery pipeline using Leishmania casein kinase 1 isoform 2 to identify compounds with antileishmanial activity. Antimicrobial Agents and Chemotherapy 60, 2822-2833.

El Fadili K, Messier N, Leprohon P, Roy G, Guimond C, Trudel N, Saravia NG, Papadopoulou B, Legare D and Ouellette M (2005) Role of the ABC transporter MRPA (PGPA) in antimony resistance in Leishmania infantum axenic and intracellular amastigotes. Antimicrobial Agents and Chemotherapy 49, 1988-1993.

Fairlamb AH, Blackburn P, Ulrich P, Chait BT and Cerami A (1985) Trypanothione: a novel bis(glutathionyl)spermidine cofactor for glutathione reductase in trypanosomatids. Science 227, 1485-1487.

Faraut-Gambarelli F, Piarroux R, Deniau M, Giusiano B, Marty P, Michel G, Faugere B and Dumon H (1997) In vitro and in vivo resistance of Leishmania infantum to meglumine antimoniate: a study of 37 strains collected from patients with visceral leishmaniasis. Antimicrobial Agents and Chemotherapy 41, 827-830.

Garnier T, Brown MB, Lawrence MJ and Croft SL (2006) In-vitro and in-vivo studies on a topical formulation of sitamaquine dihydrochloride for cutaneous leishmaniasis. Journal of Pharmacy and Pharmacology 58, 1043-1054.

Gelband H, Panosian C and Arrow KJ (2004) Saving Lives, Buying Time: Economics of Malaria Drugs in an age of Resistance. Washington, DC: National Academies Press (US).

Gonzalez IJ, Desponds C, Schaff C, Mottram JC and Fasel N (2007) Leishmania major metacaspase can replace yeast metacaspase in programmed cell death and has arginine-specific cysteine peptidase activity. International Journal for Parasitology 37, 161-172.

Grant KM, Hassan P, Anderson JS and Mottram JC (1998) The crk3 gene of Leishmania mexicana encodes a stage-regulated cdc2-related histone $\mathrm{H} 1$ kinase that associates with p12. Journal of Biological Chemistry 273, 10153-10159.
Guerin PJ, Olliaro P, Sundar S, Boelaert M, Croft SL, Desjeux P, Wasunna MK and Bryceson AD (2002) Visceral leishmaniasis: current status of control, diagnosis, and treatment, and a proposed research and development agenda. The Lancet Infectious Diseases 2, 494-501.

Gupta S, Yardley V, Vishwakarma P, Shivahare R, Sharma B, Launay D, Martin D and Puri SK (2014) Nitroimidazo-oxazole compound DNDI-VL-2098: an orally effective preclinical drug candidate for the treatment of visceral leishmaniasis. Journal of Antimicrobial Chemotherapy 70, 518-527.

Hadighi R, Mohebali M, Boucher P, Hajjaran H, Khamesipour A and Ouellette M (2006) Unresponsiveness to glucantime treatment in Iranian cutaneous leishmaniasis due to drug-resistant Leishmania tropica parasites. PLoS Medicine 3, e162.

Hassan P, Fergusson D, Grant KM and Mottram JC (2001) The CRK3 protein kinase is essential for cell cycle progression of leishmania mexicana. Molecular \& Biochemical Parasitology 113, 189-198.

Herwaldt BL (1999) Leishmaniasis. Lancet 354, 1191-1199.

Hiam A, Sebastien D, George B, Arlette F, Kalil J and Le Pape P (2006) Microtubule target for new antileishmanial drugs based on ethyl 3-haloacetamidobenzoates. Journal of Enzyme Inhibition and Medicinal Chemistry 21, 305-312.

Hijjawi N, Kanani KA, Rasheed M, Atoum M, Abdel-Dayem M and Irhimeh MR (2016) Molecular diagnosis and identification of Leishmania species in Jordan from saved dry samples. BioMed Research International, 2016, 6871739.

http://www.centerwatch.com/drug-information/fda-approved-drugs/year/2016. https://www.cdc.gov/dpdx/leishmaniasis/index.html.

Jha TK, Sundar S, Thakur CP, Felton JM, Sabin AJ and Horton J (2005) A phase II dose-ranging study of sitamaquine for the treatment of visceral leishmaniasis in India. American Journal of Tropical Medicine and Hygiene 73, 1005-1011.

Jhingran A, Chawla B, Saxena S, Barrett MP and Madhubala R (2009) Paromomycin: uptake and resistance in Leishmania donovani. Molecular \& Biochemical Parasitology 164, 111-117.

Kandpal M and Tekwani BL (1997) Polyamine transport systems of Leishmania donovani promastigotes. Life Sciences 60, 1793-1801.

Knippschild U, Gocht A, Wolff S, Huber N, Löhler J and Stöter M (2005) The casein kinase 1 family: participation in multiple cellular processes in eukaryotes. Cellular Signalling 17, 675-689.

Kumar A, Boggula VR, Sundar S, Shasany AK and Dube A (2009) Identification of genetic markers in sodium antimony gluconate (SAG) sensitive and resistant Indian clinical isolates of Leishmania donovani through amplified fragment length polymorphism (AFLP). Acta Tropica 110, 80-85.

Kumar A, Sisodia B, Misra P, Sundar S, Shasany AK and Dube A (2010) Proteome mapping of overexpressed membrane-enriched and cytosolic proteins in sodium antimony gluconate (SAG) resistant clinical isolate of Leishmania donovani. British Journal of Clinical Pharmacology 70, 609-617.

Kumar S, Ali MR and Bawa S (2014) Mini review on tricyclic compounds as an inhibitor of trypanothione reductase. Journal of Pharmacy and Bioallied Sciences 6, 222-228.

Kumar A, Misra P, Sisodia B, Shasany AK, Sundar S and Dube A (2015) Proteomic analyses of membrane enriched proteins of Leishmania donovani Indian clinical isolate by mass spectrometry. Parasitology International 64, 36-42.

Laniado-Laborin R and Cabrales-Vargas MN (2009) Amphotericin B: side effects and toxicity. Revista Iberoamericana de Micologia 26, 223-227.

Lee N, Gannavaram S, Selvapandiyan A and Debrabant A (2007) Characterization of metacaspases with trypsin-like activity and their putative role in programmed cell death in the protozoan parasite Leishmania. Eukaryotic Cell 6, 1745-1757.

Lira R, Sundar S, Makharia A, Kenney R, Gam A, Saraiva E and Sacks D (1999) Evidence that the high incidence of treatment failures in Indian kala-azar is due to the emergence of antimony-resistant strains of Leishmania donovani. Journal of Infectious Diseases 180, 564-567.

Lorente SO, Jimenez CJ, Gros L, Yardley V, de Luca-Fradley K, Croft SL, A Urbina J, Ruiz-Perez LM, Pacanowska DG and Gilbert IH (2005) Preparation of transition-state analogues of sterol 24-methyl transferase as potential anti-parasitics. Bioorganic \& Medicinal Chemistry 13, 5435-5453.

Maltezou HC (2010) Drug resistance in visceral leishmaniasis. Journal of Biomedicine \& Biotechnology 2010, 617521.

Marcondes M, Biondo AW, Gomes AA, Silva AR, Vieira RF, Camacho AA, Quinn J and Chandrashekar R (2011) Validation of a Leishmania infantum ELISA rapid test for serological diagnosis of Leishmania chagasi in dogs. Veterinary Parasitology 175, 15-19. 
Meslin B, Zalila H, Fasel N, Picot S and Bienvenu AL (2011) Are protozoan metacaspases potential parasite killers? Parasites \& Vectors 4, 26.

Moore EM and Lockwood DN (2010) Treatment of visceral leishmaniasis. Journal of Global Infectious Diseases 2, 151-158.

Pace D (2014) Leishmaniasis. The Journal of Infection, 69(Suppl 1), S10-18.

Padmanabhan PK, Samant M, Cloutier S, Simard MJ and Papadopoulou B (2012) Apoptosis-like programmed cell death induces antisense ribosomal RNA (rRNA) fragmentation and rRNA degradation in Leishmania. Cell Death and Differentiation 19, 1972-1982.

Padmanabhan PK, Zghidi-Abouzid O, Samant M, Dumas C, Aguiar BG, Estaquier J and Papadopoulou B (2016) DDX3 DEAD-box RNA helicase plays a central role in mitochondrial protein quality control in Leishmania. Cell Death \& Diseases 7, e2406.

Patterson S, Wyllie S, Stojanovski L, Perry MR, Simeons FR, Norval S, Osuna-Cabello M, De Rycker M, Read KD and Fairlamb AH (2013) The R enantiomer of the antitubercular drug PA-824 as a potential oral treatment for visceral leishmaniasis. Antimicrobial Agents and Chemotherapy 57, 4699-4706.

Perez-Victoria JM, Parodi-Talice A, Torres C, Gamarro F and Castanys S (2001) ABC transporters in the protozoan parasite Leishmania. International Microbiology 4, 159-166.

Pérez-Victoria FJ, Sánchez-Cañete MP, Seifert K, Croft SL, Sundar S, Castanys S and Gamarro F (2006) Mechanisms of experimental resistance of Leishmania to miltefosine: implications for clinical use. Drug Resistance Updates 9, 26-39.

Perry MR, Prajapati VK, Menten J, Raab A, Feldmann J, Chakraborti D, Sundar S, Fairlamb AH, Boelaert M and Picado A (2015) Arsenic exposure and outcomes of antimonial treatment in visceral leishmaniasis patients in Bihar, India: a retrospective cohort study. PLoS Neglected Tropical Diseases 9, e0003518.

Pfaller MA and Marr JJ (1974) Antileishmanial effect of allopurinol Antimicrobial Agents and Chemotherapy 5, 469-472.

Roberts SC, Jiang Y, Gasteier J, Frydman B, Marton LJ, Heby O and Ullman B (2007) Leishmania donovani polyamine biosynthetic enzyme overproducers as tools to investigate the mode of action of cytotoxic polyamine analogs. Antimicrobial Agents and Chemotherapy 51, 438-445.

Rojas R, Valderrama L, Valderrama M, Varona MX, Ouellette $M$ and Saravia NG (2006) Resistance to antimony and treatment failure in human Leishmania (Viannia) infection. Journal of Infectious Diseases 193, 1375-1383.

Sachs JD (2002) Macroeconomics and health: investing in health for economic development. Revista Panamericana de Salud Pública 12, 143-144.

Saenz RE, Paz HM, Johnson CM, Marr JJ, Nelson DJ, Pattishall KH and Rogers MD (1989) Treatment of American cutaneous leishmaniasis with orally administered allopurinol riboside. Journal of Infectious Diseases 160, 153-158.

Salem MM and Werbovetz KA (2005) Antiprotozoal compounds from Psorothamnus polydenius. Journal of Natural Products 68, 108-111.

Schröder J, Noack S, Marhöfer RJ, Mottram JC, Coombs GH and Selzer PM (2013) Identification of semicarbazones, thiosemicarbazones and triazine nitriles as inhibitors of Leishmania mexicana cysteine protease CPB. PLoS ONE 8, e77460.

Seifert K, Pérez-Victoria FJ, Stettler M, Sánchez-Cañete MP, Castanys S, Gamarro F and Croft SL (2007) Inactivation of the miltefosine transporter, LdMT, causes miltefosine resistance that is conferred to the amastigote stage of Leishmania donovani and persists in vivo. International Journal of Antimicrobial Agents 30, 229-235.

Senkovich O, Schormann N and Chattopadhyay D (2009) Structures of dihydrofolate reductase-thymidylate synthase of Trypanosoma cruzi in the folate-free state and in complex with two antifolate drugs, trimetrexate and methotrexate. Acta Crystallographica. Section D, Biological Crystallography 65, 704-716.

Sereno D, Holzmuller P, Mangot I, Cuny G, Ouaissi A and Lemesre JL (2001) Antimonial-mediated DNA fragmentation in Leishmania infantum amastigotes. Antimicrobial Agents and Chemotherapy 45, 2064-2069.

Shaked-Mishan P, Ulrich N, Ephros M and Zilberstein D (2001) Novel Intracellular SbV reducing activity correlates with antimony susceptibility in Leishmania donovani. Journal of Biological Chemistry 276, 3971-3976.

Singh AK, Papadopoulou B and Ouellette M (2001) Gene amplification in amphotericin B-resistant Leishmania tarentolae. Experimental Parasitology 99, 141-147.

Singh RK, Pandey HP and Sundar S (2006) Visceral leishmaniasis (kala-azar): challenges ahead. Indian Journal of Medical Research 123, 331-344.

Singh J, Khan MI, Singh Yadav SP, Srivastava A, Sinha KK, Ashish Das P and Kundu B (2017) L-Asparaginase of Leishmania donovani: metabolic target and its role in Amphotericin B resistance. International Journal for Parasitology - Drugs and Drug Resistance 7, 337-349.
Sundar S (2001) Drug resistance in Indian visceral leishmaniasis. Tropical Medicine \& International Health 6, 849-854.

Sundar S and Olliaro PL (2007) Miltefosine in the treatment of leishmaniasis: clinical evidence for informed clinical risk management. Therapeutics and Clinical Risk Management 3, 733-740.

Sundar S, Makharia A, More DK, Agrawal G, Voss A, Fischer C, Bachmann P and Murray HW (2000) Short-course of oral miltefosine for treatment of visceral leishmaniasis. Clinical Infectious Diseases 31, 1110-1113.

Sundar S, Jha TK, Thakur CP, Bhattacharya SK and Rai M (2006) Oral miltefosine for the treatment of Indian visceral leishmaniasis. Transactions of the Royal Society of Tropical Medicine and Hygiene, 100(Suppl 1), S26-33.

Sundar S, Chakravarty J, Rai V, Agrawal N, Singh S, Chauhan V and Murray HW (2007) Amphotericin B treatment for Indian visceral leishmaniasis: response to 15 daily versus alternate-day infusions. Clinical Infectious Diseases 45, 556-561.

Sundar S, Sinha PK, Rai M, Verma DK, Nawin K, Alam S, Chakravarty J, Vaillant M, Verma N, Pandey K, Kumari P, Lal CS, Arora R, Sharma B, Ellis S, Strub-Wourgaft N, Balasegaram M, Olliaro P, Das $P$ and Modabber F (2011) Comparison of short-course multidrug treatment with standard therapy for visceral leishmaniasis in India: an open-label, non-inferiority, randomised controlled trial. Lancet 377, 477-486.

Thakur BB (2003) Breakthrough in the management of visceral leishmaniasis. The Journal of the Association of Physicians of India 51, 649-651.

Veras P, Brodskyn C, Balestieri F, Freitas L, Ramos A, Queiroz A, Barral A, Beverley S and Barral-Netto M (1999) A dhfr-ts- Leishmania major knockout mutant cross-protects against Leishmania amazonensis. Memorias do Instituto Oswaldo Cruz 94, 491-496.

Vimal A and Kumar A (2017) In vitro screening and in silico validation revealed key microbes for higher production of significant therapeutic enzyme L-asparaginase. Enzyme and Microbial Technology 98, 9-17.

Walker KF, Arfin SM, Bradshaw RA (eds) (1998) Handbook of Proteolytic Enzymes London: Academic Press, pp. 1394-1399.

Wang J, Leblanc E, Chang CF, Papadopoulou B, Bray T, Whiteley JM, Lin SX and Ouellette $\mathbf{M}$ (1997) Pterin and folate reduction by the Leishmania tarentolae $\mathrm{H}$ locus short-chain dehydrogenase/reductase PTR1. Archives of Biochemistry and Biophysics 342, 197-202.

Wasunna MK, Rashid JR, Mbui J, Kirigi G, Kinoti D, Lodenyo H, Felton JM, Sabin AJ, Albert MJ and Horton J (2005) A phase II dose-increasing study of sitamaquine for the treatment of visceral leishmaniasis in Kenya. American Journal of Tropical Medicine and Hygiene 73, 871-876

Wiese M (2007) Leishmania MAP kinases--familiar proteins in an unual context. International Journal for Parasitology 37, 1053-1062.

Williams D, Mullen AB, Baillie AJ and Carter KC (1998) Comparison of the efficacy of free and non-ionic-surfactant vesicular formulations of paromomycin in a murine model of visceral leishmaniasis. Journal of Pharmacy and Pharmacology 50, 1351-1356.

Wiwanitkit V (2012) Interest in paromomycin for the treatment of visceral leishmaniasis (kala-azar). Therapeutics and Clinical Risk Management 8, 323-328.

Wyllie S, Patterson S, Stojanovski L, Simeons FR, Norval S, Kime R, Read KD and Fairlamb AH (2012) The anti-trypanosome drug fexinidazole shows potential for treating visceral leishmaniasis. Science Translational Medicine 4, 119re111.

Xingi E, Smirlis D, Myrianthopoulos V, Magiatis P, Grant KM, Meijer L, Mikros E, Skaltsounis AL and Soteriadou K (2009) 6-Br-5methylindirubin-3'oxime (5-Me-6-BIO) targeting the leishmanial glycogen synthase kinase-3 (GSK-3) short form affects cell-cycle progression and induces apoptosis-like death: exploitation of GSK-3 for treating leishmaniasis. International Journal for Parasitology 39, 1289-1303.

Xu S, Peng G, Wang Y, Fang S and Karbowski M (2011) The AAA-ATPase p97 is essential for outer mitochondrial membrane protein turnover. Molecular Biology of the Cell 22, 291-300.

Yasur-Landau D, Jaffe CL, David L and Baneth G (2016) Allopurinol resistance in Leishmania infantum from dogs with disease relapse. PLoS Neglected Tropical Diseases 10, e0004341.

Zhang P, Nicholson DE, Bujnicki JM, Su X, Brendle JJ, Ferdig M, Kyle DE, Milhous WK and Chiang PK (2002) Angiogenesis inhibitors specific for methionine aminopeptidase 2 as drugs for malaria and leishmaniasis. Journal of Biomedical Science 9, 34-40.

Zuccotto F, Martin AC, Laskowski RA, Thornton JM and Gilbert IH (1998) Dihydrofolate reductase: a potential drug target in trypanosomes and leishmania. Journal of Computer-aided Molecular Design 12, 241-257. 